\title{
MOTIVAR PARA LA MISIÓN
}

DOI: https://doi.org/10.52039/seminarios.v56i195-196.424

OVIDIO PECHARROMÁN ${ }^{1}$

\section{INTRODUCCIÓN}

El asunto de la motivación de sus actos llama la atención a todo ser humano y en todas las etapas de su vida. Así, el por qué de sus actos interesa tanto al niño como al joven, al adulto o al anciano.

En la primera parte del presente 'vademécum' sobre las motivaciones se explica con moderada claridad lo que es un motivo y las clases de motivos que manejamos en la vida. En la segunda parte declaramos el modo como los motivos pueden llevarse a la vida de manera provechosa. En la tercera, mostramos el resultado de una motivación bien gestionada: el ser humano, hombre o mujer, maduro. Finalmente, en la cuarta parte, ofrecemos un ejemplo de motivación o condensado motivacional. Con él cerramos el trabajo.

\section{NOCIÓN DE MOTIVACIÓN}

Motivar es persuadir a una persona a decidirse por aquello que es bueno para ella. Aquello que nos mueve y pone en acción hacia un valor es un motivo.

Ejemplo de valores que mueven a las personas son los siguientes: dinero, orgullo, sexo, ciencia, religión, familia, belleza, salud, alimento, justicia...

Nuestra voluntad responde solo a motivos, es decir, a algo que se percibe como bueno para el individuo, para mí.

Las palabras que nos emocionan o estremecen son, de ordinario, palabras o situaciones que actúan como "motivo".

Una motivación clara, de perfiles bien definidos, no ocurre con la facilidad que a primera vista parece y, con frecuencia, no entendemos nuestros propios motivos (Groeschel).

Al elaborar una decisión me encuentro con motivos nobles y motivos menos nobles. Los menos nobles no dan la cara del todo.

Un grupo o constelación de motivos puede originar lo que llamamos 'ideal' de la persona; frecuentemente personificado en un modelo real de la vida, o solo posible. Cuando el ideal, o un motivo, atraen intensamente y de modo cons-

1. Sacerdote Operario Diocesano. Ha sido director del Apostolado Hispano de la Diócesis de Arlington (Virginia, EEUU). En la actualidad dirige el Sol Vocational Institute que la Hermandad de Sacerdotes Operarios tiene en Washington D.C. Es autor de varias obras sobre evangelización, misión y psicología de la vocación cristiana. 


\section{Ovidio Pecharromán}

tante a la voluntad, hacen de ésta una "voluntad fuerte", es decir, firme y digna de confianza. Es ésta una preciosa y codiciada forma de voluntad que se obtiene a base de repetición, a base de acciones constantemente motivadas y repetidas (en buenos y malos momentos), y a las que la persona se habitúa. Y porque nos hemos habituado a ella podemos contar con ella como si fuera un perro pastor. Esta voluntad sostiene el propósito de la vida y su caminar. ¡Es una voluntad motivada!

La palabra a tener aquí en cuenta es repetición, tan importante en el caminar vocacional y en la vida de crecimiento.

Para lograr el valor, que nos moviliza en forma de motivo, éste, el motivo, debe poseer un rostro característico, a saber: debe llamar mucho la atención de la persona; debe durar -no ser cosa de un día- para toda la vida; debe abarcar todas las plataformas personales: sensibilidad, afectos, área imaginativa, área del recuerdo, plataforma libre y plataforma del entender. (El motivo, en efecto, hace vibrar a toda la persona). Finalmente, debemos ser conscientes del motivo siempre. Así pues, los agentes motivadores son los que ponen en marcha a la voluntad y la hacen caminar en situaciones fáciles y difíciles.

En breve: motivar es ver con cierto grado de fascinación un propósito, una meta muy valiosa que podemos conseguir. El ir tras esta meta se articula ordinariamente en forma de proyecto de vida. El proyecto de vida debe sentir el pulsar de los motivos siempre. Y el caminante vocacional debe consultar con alguien que ya conozca el camino.

\section{LAS APETENCIAS}

Frente a la motivación existe el mundo de las apetencias -de lo agradable y lo desagradable- que brota del deseo y surge de la atracción del entorno exterior. Se relaciona preferentemente con el mundo de las sensaciones. Si los motivos configuran más el proyecto y, de algún modo, aspiran a la mejora personal, las apetencias responden a algo momentáneo, que puede llegar incluso a frenar el proyecto o comprometer la libertad personal... aunque eso sea difícil de ver al principio.

Desde luego; emoción y motivación son palabras hermanas que nos conviene diferenciar bien. Nos dice la vida que cuando obramos o construimos algo sobre la base de las emociones -motivados por ellas- la construcción resulta deficiente o francamente mala. Pero, en esta área no escarmentamos fácilmente.

En la construcción del edificio vocacional la motivación nos impulsa a comenzar y el hábito a continuar (R. Ryun). Ya hemos subrayado la importancia de la repetición.

Motivar a una persona consiste en presentarle un bien que le atraiga, como sabemos. Un motivo es un bien atrayente; para que este sea eficaz y actúe, debe 
ser: adaptado, duradero, consciente y comprensivo o abarcador. Los motivos pueden venir de la sociedad (sociales), de la vida misma (vitales), de los sentidos (sensuales), de las cosas materiales (materiales), y de la religión (religiosos).

Por otra parte, el movimiento de la libertad en su marcha hacia el valor hay que sostenerlo, alabarlo, retarlo, acompañarlo, y bendecirlo.

Resumiendo. El motivo o motivación vocacional no coincide en nosotros con el mundo de la apetencia. Distingámoslo. Las apetencias no son capaces de sostener la misión; la motivación madura sí. Quien discierne una vocación auténtica debe aplicar aquí su «ojo de buen cubero», su instinto, para no tomar por motivo realidades de la persona que no lo son. Debe poseer también una aguda sensibilidad para descubrir enseguida el «tono y cualidad» de los motivos y su procedencia. Y una vez calibrada bien la motivación, sostenerla.

\section{NECESIDADES Y VALORES OBJETIVOS}

En cuanto se refiere a motivación, debemos distinguir entre lo que es importante para mí y lo que es importante en sí (Lonergan). Lo importante para mi lleva a lo que satisface a la persona. Pero lo importante en sí puede llevar a que uno prescinda de sí mismo y pueda transcenderse. El criterio, 'lo importante para mí', me gusta, no basta para fundamentar una acción libre y no garantiza, tampoco, que se persevere en esa acción.

La motivación vocacional profunda y duradera debe comprender tanto las necesidades como los valores de la persona. Hay que aceptar -en el discernimiento vocacional- una tensión simultánea entre necesidades y valores.

Así pues, nuestra motivación puede ser de la cabeza o del corazón. Si no siento pasión por lo que elijo, se trata de emociones racionales, que pueden desmoronar el mundo afectivo, el cual pronto o tarde saldrá a flote y, si no hay costumbre de enfrentarlo, puede anular los valores en que antes creíamos. En la parte agradable o desagradable de las motivaciones personales el inconsciente ocupa un lugar importante. Atención, pues, a las interferencias de la memoria afectiva (P. Magna).

En nuestro sistema normal de motivaciones respecto a nuestro progreso hacia un más allá de nosotros mismos hay muchas ambigüedades (Rulla). Estas tienen que ver sobre todo con las necesidades intuitivo-emotivas, y lo que es "importante para mí". Estas motivaciones pueden ayudar, o no, a la persona a transcenderse, pero a menudo la obstaculizan en su marcha, por su egoísmo intrínseco.

Resumen. En las motivaciones, distinguir lo importante para mí de lo importante en sí. La motivación sana administra jerárquicamente ambas. Atención a las tensiones en este momento, debido a la ambigüedad en los motivos. Aquí se muestra de modo especial la talla de discernidor. 


\section{Ovidio Pecharromán}

TÉCNICAS PARA MOTIVAR Y CRITERIOS

Las sugerencias teóricas y prácticas que siguen, dichas en forma de máxima, o casi refrán, ayudan al discernidor a revisar su propia experiencia de la vida y de los hombres y a intuir ciertos armónicos de cariz antropológico no pulsados en el pentagrama motivacional sucintamente presentado y que es de utilidad grande para el educador consejero-vocacional.

Pocos motivos, claros y potentes para la vida.

Para motivar al otro, trasmite el sentimiento (entusiasmo, por ejemplo) que el bien atrayente produjo en ti (contagio).

Palabras que te han tocado a ti son palabras-motivo para otro, a quien tocarán también.

Obra y actúa no porque te guste o disguste algo, sino por razones más altas: te hace crecer, consuela a otros, etc. Nobleza, altura de motivos.

Invitación y desafío. Reta a la persona a experimentar la conducta virtuosa.

Nada ni nadie mueve tanto a obrar, motiva tanto, como la persona que nos ama: el padre, la novia, el amigo.

Apoya sus decisiones más importantes sobre los motivos más importantes.

La persona auténticamente motivada tiende a explicar lo que la mueve.

No te muevas nunca por la alabanza cortés o por evitar la indiferencia o el desprecio descortés. Razones y valores más nobles que el aprecio o desprecio de los demás deben motivar tu existir, tu vida.

En las motivaciones vocacionales hay que clarificar el lugar que ocupan los valores y los roles en la opción concreta.

Ve con claridad cuál es el motivo dominante en una decisión: qué es lo que debe regir y orientar esa decisión.

Si quieres que una cosa sea bien hecha, añade un plus de cariño hacia aquel que debe llevarla a cabo. Esta persona quizás no quiere hacerla, así es como tu motivación le inyecta el plus de energía necesario para obrar.

Cuanto más alto (desinteresado, caritativo) es el motivo, tanto más mueve.

El motivo más potente es el religioso, aun en un contexto social religiosamente neutral.

El motivo es a la libertad, a la voluntad, lo que la atención es a la inteligencia: la inyecta un suplemento de energía para actuar.

La motivación sana produce agradecimiento. Y aunque la persona agradecida no diga nada, puedes suponer su agradecimiento. Si no nos dan las gracias por nuestra motivación, es que motivamos deficientemente; fallamos en algo.

La persona motivada por valores altos es libre y no necesita para obrar el ser manipulada de ningún modo: amenazas, adulaciones, etc.

Cristo, movido por el bien supremo y el bien de este mundo para el ser humano, se presentó en la historia como el ser libre por antonomasia. Es el ejemplo siempre buscado de motivación. 
La alegría y la unión en una comunidad son debidas a una motivación alta y aceptada.

Lo nuestro es movernos hacia el bien para ser buenos, desarrollados y perfectos como hombres. Si no lo hacemos, algo en nosotros nos culpabiliza.

"Como no había amor de Dios que quitase el amor del padre y parientes, era todo haciéndome una fuerza tan grande que si el Señor no me ayuda no bastaran mis consideraciones para ir adelante" (St. Teresa de Jesús).

Toda motivación que se percibe como nacida del amor, se acepta.

"Nunca pongas los ojos en el gusto o disgusto que se te ofrece en la obra que vas a hacer, para hacerla, o dejarla de hacer, sino en la razón que hay de hacerla por Dios" (S. Juan de la Cruz)

Reúsa sentirte descorazonado, incapaz de ser movido hacia lo que es bueno; porque esa actitud no te permite crecer, que es lo que tú quieres, aunque sea difícil en la presente situación. No creas que siempre va a ser así.

Esfuérzate por ver bien quién es, por caer en la cuenta de su identidad, y no tomes un fallo o fallos por un fracaso total de su persona.

Haz algo diferente, empieza a motivarte por cosas buenas, pequeñas y fáciles de lograr. Desde ese punto tú mismo avanzarás.

No dejes tu vida cruzada de brazos, sin razón o motivo alguno para vivir. Y no exageres; porque las exageraciones son eso, 'exageraciones', no realidades que están ahí delante de nosotros.

Pon tu corazón, tu persona, en ello; como han hecho algunas grandes personas: comerciantes, artistas, religiosos, políticos y científicos.

Atrévete a confiar en las personas. Hay muchas personas que ayudan, lo dice la vida. Tú mismo quieres ayudar. Quizás no las has encontrado todavía.

Ganar confianza en uno mismo es una tarea que dura toda la vida. Pero esa confianza nos es necesaria porque nos motiva mucho y nos abre las manos para hacer el bien a otros y a nosotros mismos. Abrir las manos hacia lo bueno es un acto hermoso de motivación.

Para ganar confianza en ti mismo apóyate en las pequeñas cualidades que ya tienes, en las palabras de aliento que te dan los que te rodean y te conocen; concéntrate en un punto poco desarrollado de tu persona, servir, por ejemplo, y desde ahí ayuda a otros. Haz esto muchas veces, ya que en esta vida adquirimos todo, o casi todo, por repetición.

Prepárate y estudia; sobre todo para enriquecer las áreas de su persona con las que puedes ayudar más. Esto te dará mucha alegría, porque te motiva a servir. Y es del servir a otros de donde nos viene la alegría.

Acepta un trabajo, una pequeña obligación, o grande, que antes eras incapaz de aceptar. No te acobardes fácilmente. Nuestra imaginación nos puede hacer daño por miedos excesivos.

Mejora tu presencia personal y tus maneras. Desde fuera nos ayudamos hacia dentro. 


\section{Ovidio Pecharromán}

Evalúa tu proceso: ¿cómo lo voy haciendo? Y pregúntale a una persona prudente que lo conoce.

Pregúntate: ¿Cuáles son los ideales que guían mi vida? ¿Qué es aquello por lo que merece la pena luchar? Y añade: ¿qué pienso hacer para lograrlo?

Respecto de mis talentos para obtener los valores - por ejemplo, el sacerdocio-, ¿qué actos pongo en práctica para afianzar su capacidad y su potencial?

¿Soy consciente de que yo soy el responsable de gestionar mi vida, y por lo tanto de discernir la motivación adecuada para vivirla bien?

En mi caminar y avanzar hacia los valores, ¿controlo mis sentimientos y mis palabras e impulsos en lugar de ser controlado por ellos?

Para ayudar mi proceso de motivación debo ser consciente de mis limitaciones para vencerlas $\mathrm{o}$, al menos, para saber dónde y cómo obstaculizan mi marcha.

En la motivación, tienen un papel importante de ayuda, soporte y reto ciertas formas de hablar y afirmar. Así, son expresiones que nos motivan las siguientes:

-iLo has hecho tú!

-Vas bien

- ¡Bien hecho!

-Te estás esforzando mucho

-En eso eres muy bueno

-iBrillante!

-Felicidades

-Ya lo tienes bajo control

-Te irá muy bien

- Lo aprendes rápidamente

-Creemos en ti

-La gente te quiere y te aprecia mucho; nosotros también

UN EJEMPLO DE MOTIVACIÓN

El siguiente icono, o condensado motivacional, habla por sí mismo.

«Estamos muy agradecidos. Tienes mucho que darnos y harás mucho bien a los niños. Te suplico que vengas. Volveremos a estar muy agradecidos. Ya fue así el año pasado; así será también en el futuro. Fue tan bueno el volver a hablar contigo. Propongo esta fecha; de lo contrario dame tú una. Esto es muy importante para nuestra institución. $Y$ tus amigos nos ayudaron ya».

¿Puede desoírse semejante forma de motivar?

\section{RESULTADOS DE LA MOTIVACIÓN}

¡Con cuánto agradecimiento recordamos a las personas que nos orientaron y motivaron bien en la vida! El profundo agradecimiento acompaña a la motivación sabia y buena que florece en la bella planta de la persona buena (bella) cristiana. 
La motivación prudente, amorosa y entusiasta hace crecer seres humanos normales, equilibrados, bellos. No hay mejor resultado que éste, ni mejor cosecha de la motivación bien establecida y sembrada.

La motivación recta es un gran privilegio y presupone un corazón, una persona libre, competente y amorosa. No motiva bien una persona cualquiera, aunque muchos lo hagan. $Y$ no motiva del todo el que se presenta como mero profesional. Un suplemento de contagio personal se necesita en este dedicado ejercicio.

Motivamos cuando descubrimos -"hacemos ver"- valores a otra persona: en la calle, en la casa, en personas que nos encontramos, en eventos, en el arte, en la religión. Finalmente, en esa persona misma con quien estamos hablando, orientando, haciéndola captar de modo vivencial las propias razones-valores que tiene para que se dispongan a devenir motivos que impulsan su llamada hacia su destino en la vida.

La persona armónica, desarrollada y buena se halla lista para ser enviada a la misión. El misionero auténtico pone sus pies sobre esa preciosa plataforma humana, a saber: el hombre maduro.

Así, lo humano, que es obra de Dios, Dios lo ofrece como base para hacer su obra entre los hombres. Por el hombre-Dios, Jesucristo, fuimos predicados y salvados.

\section{BibLIOGRAFÍA}

Borile, E.-CABbiA, L.-MAgno, V., dirs., Diccionario de Pastoral Vocacional, Salamanca 2005. BALTHASAR, H.U. VON., Vocatione, Roma 1981.

Cencini, A.-Manenti, A., Psicología y Formación, México 1998.

DelHaYe, P., "La dignità della persona umana», en G. BARAúnA, La Chiesa nel modo di oggi. Studi e commenti intorno alla Costituzione Pastorale 'Gaudium et Spes', Firenze 1966, 260-286.

Doncel, J. F., Philosophical Anthropology, New York $1967^{3}$.

FaVAle, A., ed., Vocazione comune e vocazione specifiche. Aspetti biblici, teologici e psico-pedagogico-pastorali, Roma 1993.

GRESHAKE, G., Ser sacerdote hoy, Salamanca 2000.

Groeshel, R., Psicología y Espiritualidad, Salamanca 2000.

IMODA, F., Sviluppo umano, psicologia e mistero, Casale Monferrato 1993.

- (dir.), Antropologia interdisciplinare e formazione, Bologna 1997.

LADARIA, L.F., Introducción a la antropología teológica, Estella 1993.

LoNERGAN, B., Método en teología, Salamanca 1988.

LóPEZ QUINTÁs, A. Diagnosis del hombre actual, Madrid 1976.

MANenti, A., Vocazione, psicologia e grazia. Prospettive di integrazione, Bologna 1987.

MendiBoure, B. «Vers une décision de vocation responsable», Jeunnes et vocations 120 (2006) 131-139.

Muccl, G., «Crisi dei valori. Una terapia comune tra laici e cattolici», La Civiltà Cattolica 143 (1992) 450-457. 


\section{Ovidio Pecharromán}

PARENTE, M., «L'annuncio che entusiasma», Rogate ergo 1 (2006) 17-19.

Pecharroman, O., La Calidad Humana del Amor, Salamanca 1985.

PIGNA, A., La vocación: teologia y discernimento, Roma 1976.

Ratzinger, J., «The Dignity of the Human Person», en H. VoRgrimmler, ed. Commentary on the Documents of Vatican II, New York-London 1969.

RuBio, L., Nuevas vocaciones para un mundo nuevo, Salamanca 1992.

RULLA, L., Anthropology of the Christian Vocation: (I) Interdisciplinary Bases; (II) Existential Confirmation, Roma 1986.

SIVIGLIA, I., «Valori umani nei 'chiamati'», Rogate ergo 5 (2006) 6-8.

Stoetzel, J., I valori del tempo presente. Una inchiesta in Europa, Torino 1984.

VANHOYE, A. Sacerdotes antiguos, sacerdotes nuevos, según el Nuevo Testamento, Salamanca 1984. 